\title{
EDUCAÇÃO A SERVIÇO DA ENFERMAGEM \\ DESENVOLVIMENTO DO ENSINO SUPERIOR DE ENFERMAGEM NA REGIÃO CENTRO-OESTE INDICADORES DE QUALIDADE PARA CURSOS DE GRADUAÇÃO
}

\author{
Maria da Glória Miotto Wright * \\ Lygia Paim ** \\ Kazue Horigoshi Rodrigues ***
}

ReBEn/06

WRIGHT, M.G.M. e Colaboradoras - Desenvolvimento do Ensino Superior de Enfermagem na Regiāo Centro-Oeste - Indicadores de Qualidade para Cursos de Graduaçāo. Rev. Bras. Enf.; DF, 35 : 60-73. 1982.

\section{INTRODUÇĀO}

Em 1975, o então Departamento de Assuntos Universitários do Ministério de Educação e Cultura (DAU/MEC) de posse do dado de que a Enfermagem era o curso que menos crescia no País, resolveu elaborar um documento da Área de Enfermagem, no qual se identificassem alguns dos bloqueios e sugerisse medidas de superação do problema.

A partir deste documento, foi realizado um plano de trabalho para a implementação de sugestões e recomendações. Foi então que uma Assessoria de Enfermagem foi instituída no DAU/MEC e um plano de atividades proposto. Entre os componentes do plano, ficou es- tabelecido um levantamento da situação dos cursos de Graduação em Enfermagem no País, tomando-se 1975 como ano-base.

Existiam naquela ocasiāo 41 cursos de graduação em funcionamento. Deixaram de ser incluídos nesse levantamento os cursos que tiveram a sua criação em 1975, bem como aqueles que não tinham formado nenhuma turma de Enfermeiros, até 0 ano-base referido. Deste modo, os da UFGo, UFMt e UnB, objetos do presente estudo, deixaram de fazer parte daquele levantamento do DAU/MEC.

No levantamento, foi esboçada a situação dos cursos de Enfermagem num quadro que foi denominado "Padrão de

* Coordenadora do Curso de Enfermagem da UnB.

* Técnico em Desenvolvimento Científico - Coordenação de Saúde Pública - Superintendência de Desenvolvimento Social - CNPq.

*** Professor Colaborador 2 - Disciplina de Enfermagem Pediatrica e Estágio. 
WRIGHT, M.G.M. e Colaboradoras - Desenvolvimento d.o Ensino Superior de Enfermagem na Regiāo Centro-Oeste - Indicadores de Qualidade para Cursos de Graduaçāo. Rev. Bras. Enf.; DF, 35 : 60-73. 1982.

Cursos de Enfermagem de 1975", não sendo entendido como um "modelo" ou referência ideal, por se constituir apenas num perfil médio dos cursos existentes em 1975.

O Quadro Padrão-75 considerou os seguintes componentes:

1) Caracteristicas físicas, administrativas e pedagógicas dos cursos de Enfermagem disponiveis.

2) Caracteristicas reais das escolas de Enfermagem, pessoal discente e docente.

3) Técnicas e recursos de ensino.

4) Características de laboratórios de ensino.

Para a determinação de um "Modelo do Curso de Enfermagem", seria necessário estabelecer critérios para definir o "perfil" médio dos cursos de Enfermagem reconhecidos como satisfatórios 1 .

Com a finalidade de avançar no estudo e, mais tarde, definir o perfil médio dos cursos de Enfermagem satisfatórios, o Grupo Setorial de Saúde, através da Assessoria e Consultores da Comunidade de Enfermagem, elaborou um documento de uso interno sobre "Requisitos mínimos para a criação de um curso de Graduação em Enfermagem", o qual serviu de referência para o apoio técnico à implantação dos cursos mais recentes instituídos na área de graduação em Enfermagem.

Baseados também em outro documento 2 , esboçamos neste trabalho a situação dos cursos de Enfermagem na Regiāo Centro-Oeste face aos supostos indicadores de qualidade nele contidos e buscamos alguma revisão dos resultados face ao já mencionado "Padrão1975".

\section{JUSTIFICATIVA}

Atendendo às recomendações do primeiro grupo de trabalho composto de Representantes da Comunidade de Enfermagem 2, o DAU/MEC estimulou a criação de cursos de Graduação em Enfermagem em Universidades Federais cnde esses cursos não existiam.

Dentre os novos cursos, três deles se situam nas três Universidades Federais da Regiāo Centro-Oeste. São os cursos de Enfermagem da UnB, UFGo e UFMt. A época em que estes três cursos foram criados na Região CentroOeste, estava em funcionamento apenas um curso de Graduação em Enfermagem nessa regiāo.

Considerando-se que os novos cursos foram criados dentro de uma nova proposta de sistema de saúde em implantação no País, e tendo em vista que a decisão em criar tais cursos implica em igual responsabilidade em acompanhá-los no interesse de sua consolidação, buscou-se obter resposta a algumas indagações de ordem qualitativa, no esforço de explicitar alguns indicadores de desenvolvimento desses cursos de Enfermagem da Região Centro-Oeste.

Para tanto, foram componentes do instrumento, os requisitos minimos contidos no Documento DAU/MEC/GSS 3.

O citado documento contém os 15 itens a seguir explicitados:

1) Identificação de necessidades sociais para a sua criação e de-

1 Documento DAU/MEC - Desenvolvimento do Ensino Superior de Enfermagem.

2 Resultados do Grupo de Trabalho designado pelas portarias números 134/75; $138 / 75$ e 149/75 do Senhor Diretor-Geral do DAU/MEC. Assinado pelas professoras Maria Dolores Linas de Andrade (UFRJ), Maria Rosa de Souza Pinheiro (USP) e Maria Nilda Andrade (UFPe).

3 Doc. DAU/MEC/GSS - Requisitos mínimos para criação de um curso de Graduação em Enfermagem. 
WRIGHT, M.G.M. e Colaboradoras - Desenvolvimento d.o Ensino Superior de Enfermagem na Região Centro-Oeste - Indicadores de Qualidade para Cursos de Graduação. Rev. Bras. Enf.; DF, 35 : 60-73. 1982.

finição de seus objetivos e metas.

2) Continuidade do curso assegurada pela entidade mantenedora.

3) Posição do curso igual a seus pares na estrutura da entidade a que pertence.

4) Demonstração de viabilidade financeira e possibilidades de expansão.

5) Proposta de estrutura de currículo pleno (além do Mínimo CFE).

6) Proposta explícita de dinâmica curricular.

7) Fixação de Corpo Docente de Enfermagem (docentes/enfermeiros).

8) Previsão de condições e requisitos para o seu corpo discente.

9) Determinação de relação numérica máxima entre professores e alunos.

10) Indicação da área física e instalaçōes mínimas para o funcionamento regular do curso.

11) Existência de biblioteca para o ensino na área de Saúde, e especificamente para funcionamento de programas de Enfermagem.

12) Disponibilidade de recursos instrucionais audiovisuais para o desenvolvimento curricular.

13) Articulação com campos de prática diversificados (Postos, Centros de Saúde, Hospitais) assegurada com instrumento legal.

14) Definição do sistema de avaliação dos alunos e sistema de avaliação dos resultados de funcionamento do próprio Curso com base nos objetivos e metas propostas.
15) Planejamento de educação continuada de seu corpo do- cente.

\section{MATERIAL E MÉTODO}

\subsection{Amostra Populacional}

Foram admitidos na amostra os 3 cursos de Graduação em Enfermagem em funcionamento na Região CentroOeste em 1981.

\subsection{Instrumento}

Foi elaborado um questionário compcsto de 10 conjuntos de informações relativas ao Ensino Superior de Enfermagem, baseados no documento sobre os "Requisitos mínimos para o curso de Enfermagem de nível Superior". Os conjuntos explorados foram os seguintes:

- identificação;

- informação estatística: entradas e saídas de alunos;

- facilidade de ensino: instalações;

- plano curricular;

- plano de ensino;

- biblioteca;

- laboratório;

- aspectos financeiros da instituição;

- pós-graduação;

- recursos e técnicas.

\subsection{Metodologia}

Os questionários foram enviados pelo correio juntamente com o envelope selado e data pré-estabelecida para devolução dos mesmos.

Os dados obtidos foram comparados com:

- "Requisitos mínimos para curso de Enermagem de Nível Superior".

- Quadro "Padrão-75". 
WRIGHT, M.G.M. e Colaboradoras - Desenvolvimento do Ensino Superior de Enfermagem na Regiāo Centro-Oeste - Indicadores de Qualidade para Cursos de Graduação. Rev. Bras. Enf.; DF, 35 : 60-73. 1982.

— Situação do curso" de Enfermagem existente na Região CentroOeste antes de 1975.

\section{RESULTADOS OBTIDOS}

4.1. O Curso de Enfermagem identifica as necessidades sociais para sua criação e define seus objetivos e metas?
Três dos cursos de Enfermagem pesquisados informaram que na época de sua criação foi realizado levantamento das necessidades do mercado, apenas um estudou a demanda em potencial e nenhum dos cursos fez referência ao potencial de absorção dos enfermeiros que formaria.

\begin{tabular}{|c|c|c|c|}
\hline \multirow[t]{2}{*}{ UN IVERS I DADES } & NECESSIDADE & DO & DEMANDA \\
\hline & MERCADO & & POTENCIAL \\
\hline 1 & $x$ & & $x$ \\
\hline 2 & $x$ & & $x$ \\
\hline 3 & $x$ & & - \\
\hline
\end{tabular}

llustração 1. Necessidades sociais/objetivos e metas.

Ao ser criado um novo curso, o sistema formador tem mostrado pouca ou quase nenhuma relação com o sistema utilizador. Os órgãos formadores estão sobretudo preocupados com a criação do curso em si, e não tão sensível ao potencial do mercado de trabalho na absorção dos formandos. Mesmo assim, mostraram alguma preocupação em levan'tamento de necessidade de mercado, o que também, nem sempre, corresponde necessariamente a capacidade de absorção dos enfermeiros por este mesmo mercado. Certamente este é um fato pelo qual passam todos os cursos de Enfermagem do País, de vez que o currículo se propõe a formar Enfermeiro sem esta preocupação dominante de localizá-lo numa única região.

4.2. O Curso de Enfermagem está assegurado quanto a sua continuidade dentro dos objetivos da entidade mantenedora?

Todos os três cursos possuem documen'tos legais que atestam sua compatibilidade com as metas e objetivos da entidade mantenedora.

\begin{tabular}{lcc}
\hline \multirow{2}{*}{ UNIVERSIDADE } & \multicolumn{3}{c}{ TIPO/DOCUMENTC LEGAL } \\
\cline { 2 - 3 } & $\begin{array}{c}\text { ESTATUTO E REGI- } \\
\text { MENTO GERAL }\end{array}$ & $\begin{array}{c}\text { ATO DO COHSELHO } \\
\text { DIRETOR }\end{array}$ \\
\hline 1 & $\times$ & - \\
\hline 2 & $*$ & - \\
\hline 3 & - \\
\hline IIustração II. Objetivos/Entidade Mantenedora. \\
* Não respondeu
\end{tabular}


WRIGHT, M.G.M. e Colaboradoras - Desenvolvimento d.o Ensino Superior de Enfermagem na Regiāo Centro-Oeste - Indicadores de Qualidade para Cursos de Graduação. Rev. Bras. Enf.; DF, 35 : 60-73. 1982.

Um deles indisa a determinação em Estatuto e Regimento Geral. Um outro ainda não os possui e continua a ter como referência o ato legal do Conselho Diretor da Universidade. Um terceiro não mencionou qual o documento legal. A inexistência dos documentos apropriados ao andamento dos cursos pode expressar mais um bloqueio que uma facilidade para sua organização e funcionamento. Como nenhum destes cur'sos foi criado a menos de 4 anos, é de se esperar que no minimo estes documentos estejam sendo elaborados. O aceleramento deste processo deve contribuir para maior autonomia dos respectivos cursos.

4.3. O Curso de Enf.ermagem ocupa posição igual a seus pares na estrutura da entidade a que pertence?

Dois deles já se constituem em cursos especificos dentro de um Departamento de Enfermagem. Única exceção é um Curso de Enfermagem que está localizado dentro de um Departamento de Medícina Geral e Comunitária. Dos Derartamentos de Enfermagem, um deles engloba também o curso de Nutrição, o que ainda que se compreenda como medida transitória por economia de custos, se reflete em dificuldades de autonomia para ambos.

Quanto à chefia, os Departamentos de Enfermagem contam rom chefia de docente/enfermeiro, designado por portaria ou outro documento legal. Onde não foi constituído um Departamento específico de Enfermagem pelo menos a Coordenação do Curso é exercida por um docente-enfermeiro designado também por um documento legal.

O fato de que todos os cursos examinados têm a liderança de docenteenfermeiro feita por indicação baseada em ato legal, expressa que as iniciativas já empreendidas ou as dificuldades ainda existentes dependem, para sua resolução, principalmente, dessas lideranças.

Em dois dos curcos, a posição administrativa é a mesma de outros cursos da instituição (Chefias de Departamento). No terceiro, a proposta é de tornar-se Departamento, no mais breve tempo possível.

Além disso, verificou-se que nas 3 instituições existe uma portaria ou ato oficial designando dosente-enfermeiro em grupos decisórios: comissões multidisciplinares; representação em colegiados, tais como: Conselho de Ensino e Pesquisa e ainda grupos de trabalho em assessoria.

\begin{tabular}{|c|c|c|c|}
\hline & DEPARTAMENTO DE & CHEF IADO POR & DOCENTE/EN \\
\hline \multirow[t]{3}{*}{ UNIVERS I DADE } & ENFERMAGEM & DOCENTE-EN - & FERMEIRO \\
\hline & & FERME I RO & EM CARGOS \\
\hline & & & DECISORIOS \\
\hline 1 & - & $x$ & $x$ \\
\hline 2 & $x$ & $x$ & $x$ \\
\hline 3 & $x$ & $x$ & $x$ \\
\hline
\end{tabular}

llustraçāo 111 . Posiçāo na estrutura. 
WRIGHT, M.G.M. e Colaboradoras - Desenvolvimento do Ensino Superior de Enfermagem na Regiāo Centro-Oeste - Indicadores de Qualidade para Cursos de Graduação. Rev. Bras. Enf.; DF, 35 : 60-73. 1982.

Portanto, a participaçāo em grupos decisórios é mencionada em todos os cursos examinados, alguns em colegiados de ensino e pesquisa e outros em comissōes assessoras destes grupos. De toda forma a participação está assegurada, e o acesso às decisões é conseqüência deste posicionamento.

Verificou-se também que todas as instituições dispõem do seguinte pessoal administrativo não específico para o curso de Enfermagem: secretária, datilógrafo, arquivista, almoxarife e outros.

O pessoal administrativo não ser específico é compreensivel dentro de cursos que ainda não se estruturam como grandes cursos na Universidade; por outro lado, mesmo os cursos mais antigos e maiores, têm muitas vezes esta mesma situação a título de medida racionalizadora, muito estimulada a partir da reforma Universitária.

4.4. O Curso de Enfermagem demonstra viabilidade financeira para suas necessidades e registra possibilidades de expansão?

Quanto à subordinação administrativo-financeira, a amostra ccnstou de três instituições federais, uma delas caracterizada como uma fundaçāo.

Quanto à alocação de verbas, duas instituições responderam que possuem verbas para o curso de Enf :rmagem e a decisão para distribuição desta verba é a nivel de Departamento. Uma instituição referiu não possuir verbas.

\begin{tabular}{|c|c|c|c|}
\hline AOHIN!STRATIVO/ & ANO DE & NNo & $\%$ \\
\hline FINANCEIRA & $C R \mid A C \subset A O$ & ABSOL UTO & \\
\hline Universidade Federal & 1976 & 2 & $75 \%$ \\
\hline \multicolumn{4}{|l|}{ Fundação } \\
\hline Universidade Federal & 1975 & 1 & $25 \%$ \\
\hline
\end{tabular}

Acrescente-se a todo este quadro a informação de que dois dos cursos contam com alocação de recursos financeiros e um deles omitiu este tipo de informação. Também nesse sentido, por menor que seja a verba recebida, isto insinua algum grau de autonomia. $O$ avanço destes cursos deverá ser indicado também pela quantidade de verba a eles destinada, desde que esteja comprométida previamente a sua utilizaçāo, por instrumento técnico, ou seja, apresentada, discutida e avaliada em orçamentosprograma as rubricas de receitas $\theta$ despesas dos referidos oursos.

4.5. O Curso de Enfermagem apresenta proposta de estrutura de currículo pleno, tendo em vista o currículo minimo instituído pelo Conselho Federal de Educação (CFE), com disciplinas complementares ao atendimento das peculiaridades de saúde da regiāo e necessidades de aluno.

As três insti'tuições apresentam estrutura de currículo plenc.

Uma das instituições informou que seu currículo já sofreu alterações no que se refere a mudanças de pré-requisitos e número de créditos; as demais ainda nāo fizeram qualquer tipo de alteração, mas pretendem algumas, tais como: aumentar carga horária, incluir novas disciplinas e estender o curso para 4 anos. 
WRIGHT, M.G.M. e Colaboradoras - Desenvolvimento do Ensino Superior de Enfermagem na Regiāo Centro-Oeste - Indicadores de Qualidade para Cursos de Graduaçāo. Rev. Bras. Enf.; DF, 35 : 60-73. 1982.

\begin{tabular}{|c|c|c|c|c|c|c|c|c|}
\hline \multirow{3}{*}{$\begin{array}{l}\text { INSTI } \\
\text { TUI - } \\
\text { ÇOES }\end{array}$} & \multirow{3}{*}{$\begin{array}{l}\text { CURRTCULO } \\
\text { PLENO }\end{array}$} & \multirow{2}{*}{\multicolumn{2}{|c|}{$\begin{array}{l}\text { ALTERAÇĀO/ } \\
\text { CURRICULO }\end{array}$}} & \multirow{3}{*}{$\begin{array}{l}\text { ALTERAÇĀO } \\
\text { PRE-RE - } \\
\text { QUISITO }\end{array}$} & \multirow{3}{*}{$\begin{array}{l}\text { O FEITA } \\
\text { NO CRE } \\
\text { DITOS }\end{array}$} & \multirow{2}{*}{\multicolumn{3}{|c|}{$\begin{array}{l}\text { ALTERAÇÃO PRETENOI } \\
\text { DA: AUMENTAR }\end{array}$}} \\
\hline & & & & & & & & \\
\hline & & SIM & NÃO & & & $\begin{array}{l}\text { CREDI } \\
\text { TOS }\end{array}$ & $\begin{array}{l}\text { DISCI } \\
\text { PLI I } \\
\text { NA }\end{array}$ & $\begin{array}{l}\text { PERTO- } \\
\text { DOLE- } \\
\text { TIVO }\end{array}$ \\
\hline 1 & $x$ & $x$ & & $x$ & $x$ & - & - & - \\
\hline 2 & $x$ & & $x$ & - & - & - & - & - \\
\hline 3 & $x$ & & $x$ & - & - & $x$ & $x$ & $x$ \\
\hline
\end{tabular}

Quanto ao currículo, todas as instituiçōes, ainda que por obrigatoriedade, cumpram o currículo mínimo, referem à necessidade de novas formas de funcionamento curricular, todas tendem a uma mudança de formas de funcionamento, o que vem traduzindo, de algum modo, uma inquietação mais geral na área de enfermagem quando se examina cursos de outras regiōes e movimentos da classe neste sentido.

Todos os cursos compõem o seu currículo pleno com disciplinas mais ligadas à iniciação, à pesquisa. É de se notar que dentre as complementares, os métodos e técnicas voltados para a pesquisa aplicada à enferma,gem foram disciplina indicada em dois entre os três examinados. Um curso foi omisso quanto a este item.

Supōe-se pelas iniciativas de outros cursos, de associações, de estudo produzido pela Comissão de Especialistas do Ensino de Enfermagem do MEC (exis- tente até abril/81) que é preciso considerar no currículo de Graduação em Enfermagem a iniciação em pesquisa como um indicador de qualidade na formação de enfermeiros.

4.6. O Curso de Enfermagem explicita a dinâmica curricular proposta.

Todos os cursos apresentam programas de ensino com enfoque disciplinar constituído de: ementa, objetivos, conteúdo programático, cronograma e previsão de avaliação.

Todos os cursos evoluíram sem interrupção, sendo que dois deles oferecem 1 exame ves'tibular por semestre e um deles o exame vestibular é anual.

Em todos os cursos, o desenvolvimento se dá em turnos diurnos.

Quanto à duração, dois apresentam 4 períodos acadêmicos ( 4 anos) em $8 \mathrm{pe}$ rícdos letivos; e um deles apresenta 3 períodos acadêmicos ( 3 anos) em 6 períodos letivos.

\begin{tabular}{|c|c|c|c|c|c|c|}
\hline \multirow{2}{*}{$\begin{array}{l}\text { UN IVER } \\
\text { SIDADE }\end{array}$} & \multirow{2}{*}{$\begin{array}{l}\text { EVOLUÇAO SEM } \\
\text { INTERRUPÇÃOO }\end{array}$} & \multicolumn{2}{|c|}{ VEST IBULAR } & \multirow{2}{*}{$\begin{array}{l}\text { TURNOS } \\
\text { DIURNOS }\end{array}$} & \multicolumn{2}{|c|}{ DURAÇÃO } \\
\hline & & SEMESTRAL & ANUAL & & $\begin{array}{l}\text { PER TODO } \\
\text { ACADEM. }\end{array}$ & $\begin{array}{l}\text { PER IODO } \\
\text { LETIVO }\end{array}$ \\
\hline 1 & $x$ & $x$ & & $x$ & 4 & 8 \\
\hline 2 & $x$ & & $x$ & $x$ & 4 & 8 \\
\hline 3 & $x$ & $x$ & & $x$ & 3 & 6 \\
\hline
\end{tabular}

Do ponto de vista da dinâmica curricular, a organização e documentação didática parecem suficientes, certamente a melhor qualificação se dá no curso 
WRIGHT, M.G.M. e Colaboradoras - Desenvolvimento do Ensino Superior de Enfermagem na Região Centro-Oeste - Indicadores de Qualidade para Cursos de Graduação. Rev. Bras. Enf.; DF, 35 : 60-73. 1982.

enquanto em processo. Nenhum dos cursos teve seu processo interrompido desde a sua criação, e alguns deles já receberam mais alunos do que a proposição inicial, o que pode indicar a sua viabilização sem maiores bloqueios.

4.7. O Curso de Enfermagem identifica o corpo docente de que dispõe para formação de enfermeiros?

Há um total de 51 docentes nos 3 cursos mais recentes de região CentroOeste, 48 enfermeiras e 3 enfermeiros.

Quanto à idade dos docentes, há uma variação de 25 a 55 anos distribuídos nos seguintes intervalos:

$$
\begin{gathered}
\text { Universidade } 1-50 \% \text { entre } \quad 30-40 \\
\text { anos; } 50 \% \text { mais } \\
\text { de } 40 \text { anos. }
\end{gathered}
$$

Universidade 2 - nāo respondeu.

Universidade $3-25$ a 35 anos.

A titulação apresentada pelos docentes na região foram: 1 só com Graduação; 5 com Habilitação (2 deles cursando Pós-Graduação); 40 com Especialização (2 em fase de defesa de Mestrado, 1 cursando os créditos teóricos de Mestrado, 3 cursando Pós-Graduaçāo); 2 Mestrado; 1 com Doutorado; 2 com Livre-Docência.

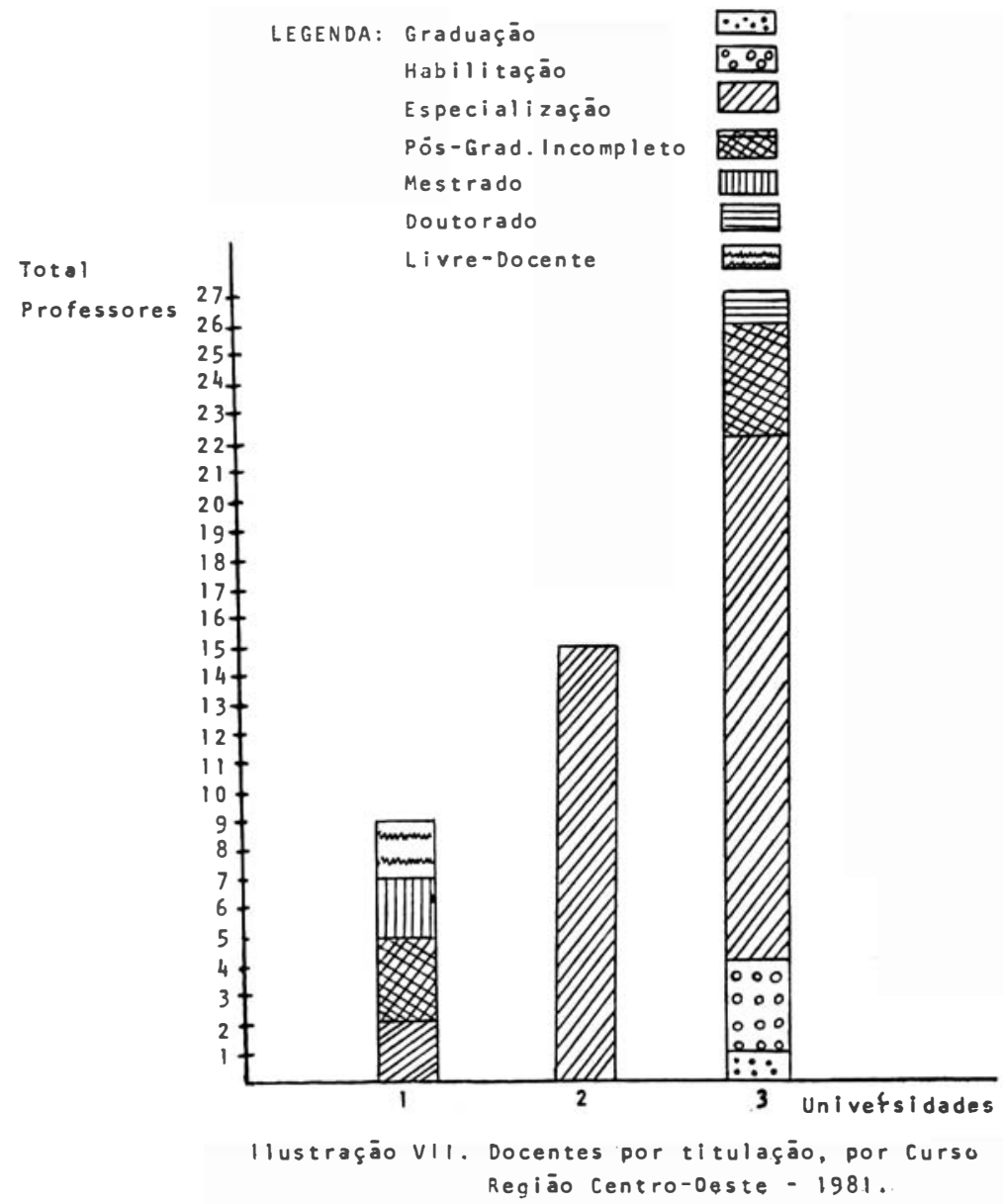


WRIGHT, M.G.M. e Colaboradoras - Desenvolvimento d.J Ensino Superior de Enfermagem na Regiāo Centro-Oeste - Indicadores de Qualidade para Cursos de Graduaçāo. Rev. Bras. Enf.; DF, 35 : 60-73. 1982.

A distribuição de horas de atividades dos docentes nas instituições examinadas varia da se 3 uinte forma:

Curso 1 - O total de horas foi distribuido em atividades administrativas, de pesquisa, didáticas e outros (sem especificação).

Curso 2 - A carga horária docente está concentrada em atividades didáticas e um minimo para outras atividades (sem especificação).

Curso 3 - A carga horária docente foi distribuida entre atividades administrativas, didáticas e outros (sem especificação).

Todos os cursos informaram a existência de previsão inicial para contratação de certo número de docentes-enfermeiros e que seus quadros não estão completos, segundo essa previsão. Observe-se que todos os cursos já foram reconhecidos oficialmente e já formaram mais de uma turma de enfermeiros e, nesse caso, é preciso fazer uma revisāo deste aspecto para ajustar previsão com a situação do curso já consolidado.

Dois dos cursos examinados têm dentro de seus planos de desenvolvimento a capacitação de seus docentes-enfermeiros no sistema forma de pós-graduação. Um dos cursos apenas não mencionou qualquer plano de capacitação docen'te.

Quanto à produção de pesquisa, somente um curso explicou suas linhas de pesquisa em enfermagem, contando, atualmente, com um total de 14 pesquisas produzidas das quais 5 já publicadas, 2 pesquisas realizadas e ainda não publicadas e 7 pesquisas em andamento, com um projeto mulidisciplinar aprovado e apoiado pelo CNPq. Nesta instituição é exigida pós-graduação (Mestrado ou Doutorado) para contrataçāo, é também exigida atividade de pesquisa de todos os docentes.

\begin{tabular}{ccccc}
\hline \multirow{2}{*}{ Universidade } & \multicolumn{4}{c}{ Atividades } \\
\cline { 2 - 5 } & Administrativa & Pesquisa & Didätica & Outros \\
\hline 1 & + & ++ & +++ & + \\
\hline 2 & - & - & ++++ & ++ \\
\hline 3 & ++ & - & ++++ & +++ \\
\hline IIustrasajo VIII & Corpo docentelatividades &
\end{tabular}

4.8. O Curso de Enfermagem prevê condições e requisitos para o seu Corpo Discente?

Quanto ao número de opções no exame vestibular, uma possibilita opção única à outra, 3 opções; e uma deixou de responder a esta questão.

Isto significa que dos 3 cursos, um deles recebe $o$ aluno com possibilidade de ser de primeira, de segunda ou de terceira opção; enquanto outro recebe alunos de única opção. Embora essa re- lação seja de grande variação, teoricamen'te se admite que a opção única indica que se recebe alunos com mais aptidão para a formação em enfermeiros. Isto passa a ser problema também quando a classificação em número de pontos é feita somente com candidatos à Enfermagem. O maior número de pontos pode ser abaixo de alunos classificados para outras áreas opcionais da Universidade.

Há uma tendência atual do aluno em fazer a opção pensando apenas em 
WRIGHT, M.G.M. e Colaboradoras - Desenvolvimento do Ensino Superior de Enfermagem na Regiāo Centro-Oeste - Indicadores de Qualidade para Cursos de Graduaçāo. Rev. Bras. Enf.; DF, 35 : 60-73. 1982.

entrar para a Universidade, tornando discutível a decisão pela escolha do curso.

Ainda com essas observações, podese notar que, em todos os 3 cursos, após a confirmação da opção pela Enfermagem, os alunos têm recebido apoio de dccen'tes-enfermeiros (orientadoresacadêmicos) o que significa maior nivel de informação e até mesmo uma tentativa de analisar o ritmo próprio de cada aluno no sentido do número e complexidade de disciplinas a ser cursado por eles em cada período.

Os 3 cursos examinados compõem a oferta de graduação em enfermagem na regiāo Centro-Oeste com aproximadamente 120 vagas anuais desde 1976. Do número de formados pode-se destacar que tem havido retenção de alunos principalmente no ciclo básico. Mesmo contando com dados insuficientes, há indicações de grande mobilização na região Centro-Oeste, de alunos do $\overline{c u r}$ so de Enfermagem para outros cursos, e de outros cursos transferidos para o curso de Enfermagem, notadamente em
Brasília, dada a sua característica de capital federal e de grande mobilidad? dos funcionários que têm universitários na família.

Em todos os cursos examinados apenas um ainda não utiliza efetivamente a representação discente nos seus colegiados. Resta buscar seu significado, visto que esta é uma participação altamente desejável, se o interessado progresso do curso é intenção clara dos corpos docente e discente desse curso. Entretanto, este item foi buscado, no geral, como um componente vitalizador da capacidade resolutiva de cada curso; mas este dado indicou certo grau de dificuldade na congruência necessária num determinado processo como o de ensinoaprendizagem de Enfermagem.

4.9. O Curso de Enfermagem descreve área física e instalações minimas para o seu funcionamento regular?

Dos dados levantados nas 3 instituições verificou-se que a característica geral é a de uso de áreas físicas comuns a outros cursos da Universidade.

\begin{tabular}{|c|c|c|c|c|c|c|c|c|c|c|c|}
\hline UNIVE & SALA & $\angle A B \underline{0}$ & AUDITO & SECRE & SALA DO & ALMO & VESTUA & SAN! & AREA DI $\underline{S}$ & CAN & AREA \\
\hline SIDADE & AULA & $\begin{array}{l}\text { RATO } \\
\text { RIO }\end{array}$ & RIO & $T A R \mid A$ & CENTES & $\begin{array}{l}\text { XAR I } \\
\text { FAD } 0\end{array}$ & RIO & $\begin{array}{l}T A- \\
R 10\end{array}$ & CENTE & $\begin{array}{l}\text { TI - } \\
\text { NA }\end{array}$ & $\begin{array}{l}\text { DEFI PRO - } \\
\text { NIT: VIS }\end{array}$ \\
\hline 1 & $x$ & $x$ & $x$ & $x$ & $x$ & $x$ & $x$ & $x$ & $x$ & $x$ & $x$ \\
\hline 2 & $x$ & $x$ & - & $x$ & $x$ & $x$ & $x$ & $x$ & - & $x$ & - \\
\hline 3 & - & $x$ & $x$ & $x$ & $x$ & $x$ & $x$ & $x$ & $x$ & $x$ & $x$ \\
\hline
\end{tabular}

As áreas mencionadas foram consideradas como definidas (não provisórias).

Todos os 3 cursos possuem laboratórios específicos de Enfermagem. Esta é uma aquisição até certo ponto discutível enquanto área imprescindivel ao funcionamento do curso. O que retrata, de modo geral a situação atual é que tais laboratórios são cópias de uniđades de internação, o que, de certo modo, re- presenta também as atividades mais comuns até então realizadas pelos alunos nos cursos de Graduação. A intensidade de uso do laboratório varia de acordo com a necessidade de aprendizagem dos alunos, segundo a indicação das respostas.

Em suma, quanto à área físiza, acomodações minimas para o funcionamento do curso de Enfermagem, todos os respondentes dizem ter, quer sejam es- 
WRIGHT, M.G.M. e Colaboradoras - Desenvolvimento do Ensino Superior de Enfermagem na Região Centro-Oeste - Indicadores de Qualidade para Cursos de Graduação. Rev. Bras. Enf.; DF, 35 : 60-73. 1982.

pecíficas ou de uso comum com outros cursos.

4.10. O Curso de Enfermagem conta com biblioteca suficiente para o ensino na área de saúde e há suficiente acervo especificamente para o funcionamento de programas do curso de Enfermagem?

As respostas indicam que existe suficiência de material nas suas bibliotecas centralizadas (não específicas para enfermagem).

Todos os 3 curscs pesquisados possuem assinaturas de revistas de Enfermagem nacionais $e$, apenas um deles possui assinatura de revistas internacionais de Enfermagem.

O fato de os cursos contarem apenas com publicações nacionais não é um indicador de suficiência, uma vez que se conta com um mínimo dessas publicações na área de Enfermagem. Por outro lado, verificou-se pelas respostas ao instrumento de coleta de dados, que os cursos têm sido atendidos em seus pedidos de novas aquisições o que nos leva a supor certa dificuldade dos que pedem, quer por desconhecimento do processo de aquisição da litera'tura internacional, quer por outra razão ainda não muito clara.

Quanto ao horário de funcionamento de bibliotecas, verificou-se que os cursos da região Centro-Oeste têm maiores oportunidades do que os outros. Isto pelo fato de que dois desses cursos utilizamse de bibliotecas que funcionam inclusive aos sábados, domingos, feriados e no período da noite ,até as 23 horas. Sem dúvida, para a Enfermagem que utiliza, quase sempre, o regime de curso em tempo integral, este também é um fator facilitador de qualidade para a busca de referencial teórico de alunos professores.
4.11. O Curso de Enfermagem dispõ de recursos instrucionais audiovisuais para seu desenvolvimento curricular?

Verificou-se que apenas numa instituição oferece-se o recurso de sistema de TV-Circuito fechado e computador e mesmo assim ainda não é utilizado pelo curso de Enfermagem, ainda que seja por outros cursos de Ciências da Saúde.

Duas das instituições dizem ter material audiovisual não específico de Enfermagem, sendo que uma delas o utiliza, e outra não respondeu à questão, somente um dos cursos possui material específico de Enfermagem, o qual é efetivamente utilizado.

Todos os 3 cursos possuem laboratórios de ensino específicos. Dois deles dizem fazer uso efetivo dos mesmos, e um não respondeu a esta parte da questão.

Sendo os recursos instrucionais um meio que favorece o desenvolvimento das estra'tégias em relação ao ensinoaprendizagem e facilitam e dinamizam a aprendizagem, nos parece que a sua utilização pelos cursos de Enfermagem da regiāo, sejam eles de uso comum aos cursos ou específicos da Enfermagem, é um fator positivo para a evolução destes cursos. A maior ou menor dificuldade em se utilizar do recurso mais sofisticado, quando o possui, pode estar ligada ao despreparo nesses aspectos de uso de tecnologia educacional.

4.12. O Curso de Enfermagem documenta sua articulação com os campos de prática assegurando a formação polivalente dos enfermeiros.

Os 3 cursos informaram considerar campos de prática obrigatórios: unidade sanitária (Postos e Cen'tros de Saúde), hospitais gerais e especializados, maternidades, ambulatórios gerais e de 
WRIGHT, M.G.M. e Colaboradoras - Desenvolvimento d. Ensino Superior de Enfermagem na Região Centro-Oeste - Indicadores de Qualidade para Cursos de Graduação. Rev. Bras. Enf.; DF, 35 : 60-73. 1982.

saúde mental, escolas de $10^{\circ}$ e $2 .^{\circ}$ graus, áreas delimitadas como grupos comunitários.

Os documentos que consolidam a prática de ensino citado foram: Ofícios prévios a cada época de utilização do campo prático (de modo geral) .

Dois cursos mantêm convênios com campos de prática. Em um dos casos a instituição possui hospital próprio além de uma Unidade de Psiquiatria e em ou'tro caso há um convênio geral com todos os campos de prática.

Todos os cur'sos possuem algum documento que assegura o campo de prática para o ensino seja sob forma de oficio emergencial, convênio ou acordo. Trata-se de um requisito importante, uma vez que os campos de prática onde se desenvolvem as atividades do estudante são essenciais para a formação do enfermeiro e estudante, professores e pessoal de serviço intervêm nas mesmas situaçōes de assistência a clientes. $O$ que se verifica ainda em relação a este item é que todos os cur'sos indicam a diversificação de campos de prática do estudante abrangendo desde instituiçōes de ensino de $1 .^{\circ}$ e $2 .^{\circ}$ graus, hospitais gerais e especializados, ambulatórios gerais e de saúde mental até cəntros de saúde, parecendo que a tendência é a formação do enfermeiro polivalente na região Centro-Oeste.

5. RESUlTADOS OBTIDOS E "PADRAO DOS CURSOS DE ENFERMAGEM-75"

Os 3 cursos, quando examinados frente ao "Padrão de cursos de enfermagem - Esboço da Situação em 1975", indicaram que quanto às carasterísticas físicas, não guardam correspondência com a organização tradicionalmente utilizada pela maioria dos cursos antes existentes, o que não significa uma impropriedade para estes cursos mais recentes, masmo porque todos dispōem de áreas físicas suficientes, ainda que não particularizada, para o seu funcionamento.

Quanto a laboratórios específicos de Enfermagem, a situação da região Centro-Oeste, atualmente, é semelhante ao "Padrão-75" mesmo quando se sabe quão questionável pode ser a utilização desses laboratórios tradicionais nos cursos de Enfermagem.

No que diz respeito à biblioteca, a região Centro-Oeste oferece maior tempo de funcionamento principalmente por manter aberta a bibliơteca inclusive aos sábados, domingos e feriados. Entretanto, o acervo relativo a periódicos internacionais se constitui numa limitação, ainda que uma delas os contenha. Em termos quantitativos está conforme o indicado no "Padrão-75". Ademais, estes cursos tendem a progredir, pois as solicitaçōes anuais feitas pelos docen'tesenfermeiros têm sido atendidas, segundo suas declaraçōes.

Quanto ao "Padrão-75", relativo a pessoal discente, o afastamento dos cursos da região Centro-Oeste não é tão grande, o que mais se afasta é o componente denominado percentual de reprovação ou desistência no ato da matrícula. Este componente na região Centro-Oeste tem sido bem maior.

Quanto ao padrão do pessoal docente, em relação ao número de enfermeiros apenas graduados, a situação da região Centro-Oeste se afasta de modo positivo, isto é, os cursos têm em seus docentes a qualificação maior que o título de graduado (enfermeiro), entretanto, persiste a concentração de qualifica ção a nivel de "pós-graduação sem tese", ou seja, pós-graduação lato sensu, mais especificamente, aperfeiçoamento ou especialização. A pós-graduação stricto sensu entre docentes enfermeiros na região Centro-Osste só osorre, mais expressivamente, em um dos cursos. Este aspecto deve ser trata- 
WRIGHT, M.G.M. e Colaboradoras - Desenvclvimento do Ensino Superior de Enfermagem na Região Centro-Oeste - Indicadores de Qualidade para Cursos de Graduação. Rev. Bras. Enf.; DF, 35 : 60-73. 1982.

do com a devida adequação. A relação esperada entre titulação obtida em. Mestrado ou Doutorado e produção de pesquisa dos dozentes deve ser positiva. Mas será que essa relação, teoricamente suposta como efetiva, é a única que traduz expectativa à produção de pesquisa na área de Enfermagem? Se a pós-graduação for considerada um meio, certamente a produção de pesquisas será o fim. Isto não se tem comportado desse modo na área de Enfermagem.

Em técnicas e recursos de ensino, o "Padrão-75" não difere do atual verificado na região Centro-Oeste, à exceção de um dos cursos que dispõe da oportunidade de utilização de alguns meios mais sofisticadcs, caso se disponha à capacitação docente para planejar e implementar o seu uso em Enfermagem.

Observa-se que, de modo geral, o padrão de qualidade nos cursos mais recen'temente criados não difere daquele "Padrão-75", referidcs os cursos mais antigos. A vantagem dos cursos mais recentes e que os mesmos têm sido atendidos em suas solicitações com certa prioridade, porque, em sua maioria, ainda vêm sendo tratados como exceção. Por outro lado, o tratamento como exceção também pode significar a desvantagem de atendimento de solicitações apenas emergenciais mais imediatistas, descurando-se um tanto da consolidação do curso, por falta de medidas mais definitórias, mais constantes. Uma outra possibilidade dos cursos mais recentes tem sido a fasilidade de acesso pela menor formalidade e menores entraves burocráticos, decorrentes da fase de estruturação por que passaram até então. Por sua vez, os cursos mais tradicionais que já venceram essa fase, estão em etapa de ganhos mais lentos, porém, quase sempre, mais solidificados. As lutas de todos os cursos são as mesmas. Elas deverão ser motivo de encontros regionais para a organização de planos de trabalho mais vigorosos em busca de uma qualidade infinita para os mesmos.

As diferenças entre o acesso menos sinuoso com medidas emergenciais e o acesso mais complexo com medidas mais solidificadas, deve representar uma unidade de estudo a ser referida nos planos de trabalho conjuntos em favor da qualificação de todos os cursos de Enfermagem.

No momento, a diferença de qualidade suposta entre cursos recentes e cursos mais antigos não se revelou, pelo menos diante dcs indicadores examinados.

Resta o interesse de agrupar os cursos em estudos regionais de qualidade dos mesmos diluindo a referência de caracterizá-los tão somente como cursos novos e an'tigos e concentrando-se no interesse de luta comum pela qualidade e adequação da formação de novos enfermeiros ao compromisso social com a população, e dos enfermeiros, tanto docentes como os de Serviços de Saúde, na capacitação científica aceitável para 0 momento em que vivemos.

\section{ALGUMAS CONCLUSÓES E EX- PECTATIVAS}

Dentre os pontos críticos levantados, a situação dos cursos da regiāo Centro-Oeste evidencia menos aspectos limitadores que o exame da situação dos cursos até 1975 , a consolidação qualitativa desses cursos tem sido mais motivo de atenção que o interesse quantitativo demonstrado no ensino de modo geral até bem pouco tempo.

As instituições de ensino superior que mantêm os referidos cursos de Enfermagem têm atentado para as colocações desses cursos empenhados na sua evolução, ainda que, quase sempre, os refira entre os cursos menores. Por sua vez, a capacidade resolutiva desses cursos depende agora da disposição dos do- 
WRIGHT, M.G.M. e Colaboradoras - Desenvolvimento do Ensino Superior de Enfermagem na Regiāo Centro-Oeste - Indicadores de Qualidade para Cursos de Graduaçāo. Rev. Bras. Enf.; DF, 35 : 60-73. 1982.

centes-enfermeiros utilizarem-se da sua própria visão de igualdade a seus pares nas instituiçōes a que pertencem.

Muitos dos aspectos que podem impor certas restriçōes ao pleno desenvolvimento destes cursos estão ligados a esse posicionamento. $\mathrm{O}$ isolamento de cada um destes cursos pode ser uma séria de restrição do desenvolvimento das condiçōes de ensino de enfermagem na região Centro-Oeste. A visão pluralista de assistência de enfermagem é ponto comum em todos os cursos examinados. A capacidade de produção de cesquisas não tæm sido evidenciada como aspecto comum em todos os cursos.

Os docentes-enfermeiros, de modo geral, nesses cursos, se ocupam tão-somente de aulas em classe e supervisão da prática de alunos em serviços de saúde. Com isso deixam de ser vistas em sua plena capacidade esperada de todos os docentes de nível superior.

As atividades de pesquisa e de extensão que atribuíram a competência científica mais plena não tem sido revelada com a evidência desejada. Por sua vez, a reunião desses cursos em estudos e pesquisas de interesse comum e legadas às diretrizes da Ciência e Tecnologia de nosso tempo poderiam construir um alto senso regional de enfermagem no Centro-Oeste e de posse desta identidade surgiria a capacidade de intercâmbio científico com outras regiōes do país, e certamente vitalizaria as relaçōes de cooperação internacional nesse campo.

Desde a implantação da Lei do Sis- tema Nacional de Saúde até os dias de hoje os cursos de Enfermagem não deram contribuição maior ao atendimento de implementação do sistema do ponto de vista da enfermagem.

A proposta esteve com os enfermeiros enquanto interpretação da lei, mas não chegou ainda a influenciar a operação curricular a qual continua com o seu ponto central na Unidade de Internação.

As funçōes e o papel dos enfermeiros em serviços básicos de saúde, por exemplo, somente agora vem sendo motivo de indicação em documentos. Esta prática ainda não é manifesta a não ser em casos raros, portanto em experiências isoladas. Não é por falta de posição igual na organização, não é por falta de docentes-enfermeiros à frente dos cursos específicos de Enfermagem, não é por falta de área física e nem mesmo por ausência de representação nos colegiados deliberativos. Porque não identificar em conjunto outras variáveis que têm influenciado o nível de progresso destes cursos. Se compará-los com um passado muito distante corremos o riscn de nos imaginar muito desenvolvidos em produção de súmero de formados, número de alunos, número de docentes, mas falta repensar o destino e a concepção do єnsino-aprendizagem e do que é a enfermagem para hoje.

Repensar ainda o espaço que temos que ocupar na contribuição científica e o desempenho além do que cs outros esperam de nós no caminho do assistir à população.

B I B L I O G R A F I A

1. DEPARTAMENTO DE ASSUNTOS UNIVERSITARIOS. Ministério da Educaçāo e Cultura. Desenvolvimento do Ensino superior de entermagem no Brasil. Brasília, 1979.

2. GSS/DAU/MEC - Requisitos minimos para cursos de Enfermagem de nivel superior. (Documento mimeografado), 1978.
3. Situaçāo de Enfermagem - 1975. (D)cumento elaborado em 1975 por solicitaçāo do DAU/MEC pelas docentes-enfermeiras: Maria Rosa de Souza Pinheiro, Maria Dolores Lins de Andrade e Maria Nilda Andrade, designadas pelas portarias número $134 / 75,138 / 75,149 / 75$ do Senhor Diretor-Geral do DAU). 